\title{
Symptomatic malignant melanoma presenting as multiple gastrointestinal polyps
}

\author{
Shauna Casey, ${ }^{1}$ Lee Dvorkin, ${ }^{2}$ Nazar Alsanjari, ${ }^{3}$ Balazs Dezso ${ }^{4}$ \\ ${ }^{1}$ Department of Cellular Pathology, NHS Basildon University Hospital, Basildon, UK; \\ 2Department of Surgery, St Marks Hospital, Harrow, UK; \\ ${ }^{3}$ Department of Cellular Pathology, Basildon and Thurrock University Hospital, Basildon, UK; \\ ${ }^{4}$ Department of Pathology, University of Debrecen, Debrecen, Hungary
}

Correspondence to Shauna Casey, shaunacasey_2003@hotmail.com

\section{Summary}

We report on a 66-year-old man with a past medical history of gout who presented to his general practitioner (GP) in July 2009 with a history of nausea and intermittent diarrhoea. He had lost $6 \mathrm{~kg}$ in weight over 6 months. His GP found he was anaemic and referred him to a gastrointestinal outpatient clinic. He went on to have a gastroscopy and colonoscopy, which revealed multiple polyps in the stomach, duodenum and colon. Histology revealed that all the polyps were malignant melanoma. He had no known history of malignant melanoma. A staging CT scan revealed multiple lung metastases and he was referred for palliative care. The patient died 4 months after diagnosis.

\section{BACKGROUND}

Malignant melanoma commonly metastasises to the gastrointestinal tract and can mimic simple polyps endoscopically. Most patients are asymptomatic and have a known primary lesion. This patient presented symptomatically with polyps in the stomach, duodenum and colon. Patients who are symptomatic have a poorer prognosis.

\section{CASE PRESENTATION}

A 66-year-old man presented to his general practitioner (GP) in July 2009 with a 1-month history of nausea and intermittent diarrhoea. He was fully independent and working as a welding engineer. He had a past medical history of gout and his only medication was naproxen 250 mg twice a day. He had lost $6 \mathrm{~kg}$ in weight over 6 months. As well as suffering from nausea and diarrhoea the patient described feeling tired and thirsty. The GP found he was anaemic, his haemoglobin level was $9.8 \mathrm{~g} / \mathrm{dl}$ and his albumin level was $20 \mathrm{~g} / 1$.

The patient attended an outpatient's clinic and his symptoms were documented as epigastric pain after eating, loss of appetite and early satiety. He denied malaena or haematuria. Abdominal and anal examinations were unremarkable. He was noted to have marked swelling of both legs, a d-dimer was negative and deep vein thrombosis was excluded. Blood results again confirmed a haemoglobin level of $9.8 \mathrm{~g} / \mathrm{dl}$.

\section{INVESTIGATIONS}

A gastroscopy was carried out and revealed five sessile pigmented polyps (largest measuring $6 \mathrm{~mm}$ ) in the stomachthe nature of the polyps were not commented on in the endoscopy report. There was also an ulcerated polyp in the second part of the duodenum believed to be benign-this polyp was not measured. The colonoscopy revealed five pigmented polyps in the colon, which were described as villous tumours, the largest measuring $40 \mathrm{~mm}$. Malignant melanoma was not suspected by the endoscopist.

Histology revealed that all the polyps were infiltrated by pleomorphic malignant cells (figure 1A). The colonic polyps were infiltrated by tumour cells with epitheliod and spindle cell morphology. There was heavy melanin pigment production consistent with malignant melanoma. The tumour cells in all of the polyps stained strongly for S100 and HB45 confirming the diagnosis.

A staging CT scan revealed multiple lung metastases with a moderate right-sided pleural effusion and enlarged axillary lymph nodes. The liver revealed multiple cysts. There were several thin-walled small bowel loops that demonstrated a coiled-spring appearance consistent with intussusception. The proximal small bowel was distended.

\section{DIFFERENTIAL DIAGNOSIS}

Metastatic malignant melanoma confirmed on histology.

\section{OUTCOME AND FOLLOW-UP}

The patient did not have any history of cutaneous melanoma but further examination in another outpatient clinic revealed multiple pigmented lesions on his trunk and legs. The patient denied ever having any of these excised and none were clinically malignant. This patient was referred for palliative care and subsequently developed cerebral metastasis. He died 4 months after diagnosis.

\section{DISCUSSION}

Around 10400 people were diagnosed with malignant melanoma in 2006 in the UK when it was the sixth most common cancer for both sexes. ${ }^{1}$ Over the last 30 years the incidence of malignant melanoma has increased more than for any other common cancer in the UK. ${ }^{1}$

Cutaneous malignant melanoma is one of the most common types of tumour to metastasise to the gastrointestinal 


\section{BMJ Case Reports}

Figure 1 (A) Melanoma cells in the submucosa of the colon. ${ }^{10}$ (B) Colonic polyp infiltrated by malignant melanoma. ${ }^{10}$ 
tract; ${ }^{2}$ however, the majority of patients with gastrointestinal metastatic melanoma are asymptomatic and only up to $4.4 \%$ are diagnosed prior to death. ${ }^{3}$ Possibly due to the lack of symptoms, only a small number of patients first present with metastatic gastrointestinal malignant melanoma.

Most patients have a known cutaneous primary lesion on presentation and metastases can occur many years after the initial presentation of the primary lesion. One case study done by Tessier et al ${ }^{4}$ reviewed patients with primary and metastatic malignant melanoma from 1960 to 2000 . They found $19 \%$ of patients with malignant melanoma developed metastasis and 24 patients $(0.8 \%)$ were symptomatic from colonic metastases. Of these 24 patients, 5 had no history of melanoma and did not have a primary lesion at the time of presentation. Some primary sites are never found; Manouras states that the incidence of gastrointestinal melanotic metastases from an unknown primary origin ranges from $4-9 \%$ in a case series. ${ }^{5}$

Reintgen et a $\beta$ carried out a retrospective analysis of 2500 patients with malignant melanoma and found 110 (4.4\%) with premortem gastrointestinal metastatic disease. However, when Das Gupta and Brasfield studied 100 autopsies of patients with known cutaneous melanoma they found 58 with small bowel metastases, 26 with stomach metastases and 22 with colonic metastases. ${ }^{6}$ Other large autopsy series have found the gastrointestinal tract to be involved in up to $60 \%$ of patients with metastatic disease. ${ }^{4}$ The inconsistency between the low incidence of clinically diagnosed gastrointestinal metastases and postmortem findings could be due to the non-specific gastrointestinal symptoms patients describe. The symptoms are similar to other types of gastrointestinal tumours-for example, abdominal pain, nausea, haematemesis, melena and weight loss.

The small intestine is the most common site for malignant melanoma metastasis and many are polypoid masses that act as leading points for intussusception, as occurred in our case. The polyps can be amelanotic (figure 1B) and may appear benign to the endoscopist. Reintgen et al found the most common sites of metastasis to be the small intestine $(35 \%)$, colon $(15.5 \%)$ and stomach $(7 \%))^{3}$

Primary gastrointestinal malignant melanoma has also been described; the most common sites are the oesophagus and anorectum. Malignant melanoma accounts for up to $0.2 \%$ of primary oesophageal tumours and up to $1.25 \%$ of malignant tumours of the anus. ${ }^{7}$ Rare cases of primary malignant melanoma have also been described in the small bowel. ${ }^{7}$ Primary intestinal melanoma tends to be more aggressive and is associated with a worse prognosis than cutaneous melanoma.

Our case is of interest as the patient was symptomatic and presented with polyps infiltrated by malignant melanoma at multiple gastrointestinal sites with no demonstrable primary lesion. Literature searches found three cases regarding colonic polyps as the initial presentation of metastatic melanoma ${ }^{8-10}$ with no history of a primary malignant melanoma.

Sacks et al ${ }^{8}$ reported a case of a 53-year-old Caucasian woman who presented with intermittent abdominal pain for several months. Contrast barium enema revealed multiple, amelanotic, sessile polyps in the splenic and hepatic flexures and in the ascending colon. The polyps were metastatic melanoma. An upper gastrointestinal series and small bowel examination were normal. No cutaneous or primary lesion could be identified. The patient had chemotherapy but she continued to deteriorate.

Another case report by Jubelirer describes a 72-year-old man admitted with a 1-month history of mild anaemia and positive stools for occult blood. ${ }^{9}$ A colonoscopy revealed 12 sessile, amelanotic, colonic polyps. Two polyps were sent for histology and revealed metastatic melanoma. This patient stated he had two dark lesions removed from his abdomen 26 years earlier but the histological sections were not available for review. This patient died after 10 months with brain metastases.

A further case report discusses a 72-year-old man who presented with vague abdominal discomfort and weight loss over 1 month. ${ }^{10}$ Colonoscopy revealed three amelanotic polyp-like lesions in the transverse colon and histopathology confirmed these to be metastatic melanoma. No cutaneous or primary lesion was found. A CT scan showed extensive intra-abdominal lymphadenopathy and a mass in the femoral triangle. Histology revealed metastatic melanoma completely replacing lymph nodes. The patient died within 8 weeks of initial presentation.

It can be difficult to distinguish whether a patient's disease is primary intestinal melanoma or metastasis from an unknown primary cutaneous melanoma. Blecker suggests the criteria for primary melanomas include lack of concurrent or previous removal of a melanoma or atypical melanocytic lesion from the skin, lack of other organ involvement and in situ change in the overlying or adjacent gastrointestinal epithelium.?

Researchers have suggested that gastrointestinal melanoma with an unknown primary site has developed from a regressed primary cutaneous melanoma. ${ }^{2}$ In the case we have presented the gastrointestinal melanoma was believed to be metastatic as numerous sites were affected and the patient had many melanocytic lesions, which, although none where documented as clinically malignant, are the likely source of disease.

This case illustrates that malignant melanoma can present symptomatically as gastrointestinal polyps in multiple sites with no known primary lesion. The polyps may not be pigmented and the symptoms are similar to other gastrointestinal tumours.

Competing interests None.

Patient consent Obtained

\section{Learnimg points}

- Malignant melanoma may present symptomatically as gastrointestinal metastasis with no known primary lesion.

- The gastrointestinal metastasis may simulate benign polyps endoscopically especially if they are not pigmented.

- The symptoms are similar to other gastrointestinal malignancies.

- All gastrointestinal polyps should be biopsied in patients with a history of melanoma. 


\section{BMJ Case Reports}

\section{REFERENCES}

1. Cancer Research UK, UK Skin Cancer Incidence Statistics, 2009 (cited 08/09/09). http://info.cancerresearchuk.org/cancerstats/types/skin/incidence/ (accessed 8 Sept 2009).

2. Lens $\mathbf{M}$, Bataille $\mathbf{V}$, Krivokapic Z. Melanoma of the small intestine. Lancet Oncol 2009; 10:516-21.

3. Reintgen DS, Thompson W, Garbutt J, et al. Radiologic, endoscopic, and surgical considerations of melanoma metastatic to the gastrointestinal tract. Surgery 1984;95:635-9.

4. Tessier DJ, McConnell EJ, Young-Fadok T, et al. Melanoma metastatic to the colon: case series and review of the literature with outcome analysis. Dis Colon Rectum 2003;46:441-7.

5. Manouras A, Genetzakis M, Lagoudianakis E, et al. Malignant gastrointestinal melanomas of unknown origin: should it be considered primary? World J Gastroenterol 2007;13:4027-9.
6. Dasgupta TK, Brasfield RD Metastatic melanoma of the gastrointestinal tract. Arch Surg 1964;88:969-73.

7. Blecker D, Abraham S, Furth EE, et al Melanoma in the gastrointestinal tract. Am J Gastroenterol 1999;94:3427-33.

8. Sacks BA, Joffe N, Antonioli DA Metastatic melanoma presenting clinically as multiple colonic polyps. AJR Am J Roentgenol 1977;129:511-13.

9. Jubelirer SJ Multiple colonic polyps as the initial presentation of malignant melanoma. W V Med J 1992;88:279-80.

10. Tak AM. Metastatic melanoma: a case of unknown site of primary origin. Internet J Gastroentero/ 2006;4(2). http://www.ispub.com/journal/ the_internet_journal_of_gastroenterology/volume_4_number_2_17/article/ metastatic_melanoma_a_case_of_unknown_site_of_primary_origin.html (accessed $\overline{6}$ Aug 2009).

This pdf has been created automatically from the final edited text and images.

Copyright 2011 BMJ Publishing Group. All rights reserved. For permission to reuse any of this content visit http://group.bmj.com/group/rights-licensing/permissions.

BMJ Case Report Fellows may re-use this article for personal use and teaching without any further permission.

Please cite this article as follows (you will need to access the article online to obtain the date of publication).

Casey S, Dvorkin L, Alsanjari N, Dezso B. Symptomatic malignant melanoma presenting as multiple gastrointestinal polyps .

BMJ Case Reports 2011;10.1136/bcr.03.2010.2866, date of publication

Become a Fellow of BMJ Case Reports today and you can:

- Submit as many cases as you like

- Enjoy fast sympathetic peer review and rapid publication of accepted articles

- Access all the published articles

- Re-use any of the published material for personal use and teaching without further permission

For information on Institutional Fellowships contact consortiasales@bmjgroup.com

Visit casereports.bmj.com for more articles like this and to become a Fellow 